\title{
DE OMBOUW VAN SURINAME
}

DOOR

DR. A. A. L. RUTGERS

Wie uit Nederland in Suriname komt en bezoeken gaat afleggen in Paramaribo, bemerkt al spoedig, dat de hoogere kringen der samenleving vrij algemeen geen heel huis, maar een boven- of benedenhuis bewonen.

Aanvankelijk doet het den nieuwkomer eenigszins zonderling aan, dat men den Procureur-Generaal, leden van den Raad van Bestuur of van het Hof van Justitie of hoofden van departementen op een bovenhuis aantreft. Bij nadere kennismaking met de plaatselijke toestanden wordt dit echter begrijpelijk. De oude patriciërhuizen van Paramaribo zijn veel te groot voor de huidige verhoudingen; ze werden reeds vóór jaren in beneden- en bovenhuizen gesplitst en ook in dien vorm zijn ze nog de beste woningen van Paramaribo.

Deze verandering in de oude heerenhuizen van Paramaribo is een beeld en een symptoom van den ombouw, welke de geheele economische en sociale structuur van Suriname heeft ondergaan en ten deele nog bezig is door te maken.

Het is een ontwikkeling, geheel tegenovergesteld aan die, welke Java heeft doorgemaakt. In de 19e eeuw is, vooral na 1870, het jaar der agrarische wetgeving, op Java naast en rustend op den inlandschen landbouw, een Europeesche grootlandbouw ontstaan. Scherp contrasteerend met de algemeene armoede der bevolking traden daardoor op Java ondernemingscentra op, waar een kleine groep van Europeesche leiders, dank zij hun intellect en energie, tot grooten rijkdom kwam. Naast en tusschen de massale, arme landbouwersbevolking ontstond de grootlandbouw met al wat daarmede samenhangt, en geleidelijk stelde zich een evenwicht in tusschen die beide.

De ontwikkelingsgang van Suriname ging daarentegen in omgekeerde richting, vooral na 1863 , het jaar der vrijmaking van de slaven.

West Indische Gids XVI 
Suriname was gedurende eenige eeuwen een zuivere plantagekolonie geweest, een echte „kolonie" in den zin van volksplanting van het moederland. De bestaansbron was landbouw, beoefend op plantages met ingevoerde werkkrachten, de slaven. De geteelde producten waren voor de wereldmarkt, voedselbouw was geheel ondergeschikt.

Tegen het eind der $19 \mathrm{e}$ eeuw heeft het Bestuur van Suriname welbewust de hand geslagen aan den ombouw van dezen grondslag van Suriname's economisch en sociaal leven. Naast den plantagelandbouw heeft het Bestuur met alle ten dienste staande middelen den kleinen landbouw bevorderd en groote sommen bestemd voor kolonisatie-doeleinden.

Economisch beteekende dit de overgang van groote eenheden, plantages onder Europeesch beheer, naar kleine bedrijfjes, gronden en grondjes, bewoond en bewerkt door een eigen boer, Creool, Britsch-Indiër of Javaan.

De plantages werden gedreven met veel kapitaal, met betaalde werkkrachten (eerst de slaven, later de contractkoelies) en produceerden enkele weinige artikelen voor de wereldmarkt (suiker, koffie, cacao). De eigenaren en leiders hadden een kans tot groote welvaart te komen, zich rijkdommen te verzamelen, maar voor de groote massa der arbeiders bestond geen kans op lotsverbetering.

De grondjes daarentegen worden bebouwd met een minimale kapitaalsaanwending door den bezitter zelven met zijn gezin, en produceeren in de eerste plaats rijst en een veelheid van andere producten voor eigen gebruik, terwijl de overschotten op de markt komen. De bezitters vinden hier allen de kans om tot meerdere welvaart te komen en velen gelukt het, hun bedrijf geleidelijk uit te breiden en hun positie te verbeteren.

Niet alleen economisch, ook sociaal heeft deze ombouw beteekenis. De toestand van honderd jaar geleden kende - zeer schematisch voorgesteld - een kleine groep van planters, plantage-eigenaren en beheerders, met groote inkomsten en een groote massa van volkomen bezitlooze slaven. Daarvoor in de plaats treedt nu een samenleving, waarin de planters, die kapitalen verdienen, verdwenen zijn, maar de bezitlooze arbeidersmassa wordt omgezet in een groote groep van kleinbezitters, waarvan enkelingen zich opwerken tot middenstanders of welgestelde boeren.

Ook deze ombouw in Suriname zal evenals de ontwikkeling van den landbouw op Java op een evenwichtstoestand tusschen 
grootlandbouw en kleinlandbouw moeten uitloopen. Bereikt is dat evenwicht op dit oogenblik zeker nog niet; ieder jaar worden een of meer plantages verkocht, waarvoor niemand zijn geld durft wagen in den grooten landbouw. Daarvoor hebben die zorgvuldig aangelegde polders met hun trenzen en sluizen, hun fabrieken en woningen, alle waarde volkomen verloren. Maar voor den kleinen landbouw heeft ingepolderde grond nog wel waarde; tien gulden per H.A. per jaar huur is er nog altijd wel van te maken, soms zelfs meer. Daarom worden de plantages, die onder den hamer komen, thans meest voor dit doel verkocht en verkaveld. En gelijk de heerenhuizen in de stad in twee woningen gesplitst worden, zoo worden deze plantages, al naar gelang van de grootte, in tientallen of honderdtallen perceelen gesplitst.

Door het geheel verschillend karakter van de plantages en den kleinlandbouw hebben zij economisch een geheel verschillende beteekenis, en reageeren zij ieder op zijn eigene wijze op de omstandigheden.

De groote landbouw produceert alleen voor de wereldmarkt en importeert, zoo noodig, de voedingsmiddelen voor eigen gebruik. Hij wordt gedreven met vreemd, goeddeels buitenlandsch (niet-Surinaamsch) kapitaal, en is geheel ingesteld op de geldhuishouding en productiefmaking van het daarin gestoken kapitaal.

De kleinlandbouwer daarentegen produceert in de eerste plaats voor eigen gebruik, en verkoopt slechts een deel van zijn product, welk deel gewoonlijk ook nog voor de binnenlandsche markt bestemd is (rijst, bananen, vruchten, melk, eieren, enz.). Bovendien plant hij een groote verscheidenheid van producten en werkt slechts bij uitzondering met vreemd kapitaal.

De gevolgen van deze structuurverschillen zijn groot, vooral in tijden van uiterst lage prijzen als de huidige. De plantages worden door hun vaste lasten en zuivere geldhuishouding tenzij het Gouvernement hulp biedt - gedwongen te sluiten, omdat zij bij voortwerken geld erbij moeten leggen om de loonen te betalen, maar de kleinlandbouwer, die geen geldloonen betaalt, minder vaste lasten heeft, en het grootste deel van zijn oogst zelf opeet, wordt veel minder getroffen en werkt door. Voor zijn bestaan maakt het weinig verschil, of de zelf geteelde rijst, die hij opeet, bij verkoop één of drie gulden opgebracht zou hebben. Zoolang hij van eigen producten leeft, heeft hij voor dat deel van zijn bestaan met de marktprijzen niet te maken.

De kleinlandbouw heeft dus in dit opzicht grooter weerstands- 
vermogen en geeft aan het economisch geheel een groote stabiliteit.

De vraag kan gesteld worden, hoever deze ombouw van Suriname's economisch leven reeds gevorderd is.

Het antwoord op deze vraag kan van twee zijden benaderd worden, eenerzijds uitgaande van den achteruitgang van den plantagelandbouw, en anderzijds van de ontwikkeling van den kleinlandbouw.

Diep treurig zijn de cijfers over den achteruitgang der plantages; drie groote cultures uit Suriname's bloeitijd: tabak, katoen en cacao zijn volkomen verdwenen. Van de ruim 100 suikerplantages uit 1833 vinden wij er thans nog slechts één. Tegenover 280 koffieplantages in het begin der 19e eeuw staan er thans nog slechts een veertigtal. Dat is alles wat er van de vele honderden plantages is overgebleven; één suikerplantage en veertig koffieplantages. Ook al houdt men rekening met de veel grootere productie per eenheid in den tegenwoordigen tijd, dan nog bewijst dit den ontstellenden achteruitgang van het grootlandbouwbedrijf. Een blik op de kaart van Suriname, waarop al die voormalige plantages nog voorkomen, doet ons met één oogopslag zien tot welk een kleine fractie van het vroegere cultuurgebied de huidige plantages zijn ingekrompen.

En het ergste daarbij is, dat de nog staande gebleven plantages nu reeds jaren achtereen verliesgevend zijn. Zonder Gouvernementshulp in den een of andere vorm zouden ook die ééne suikeronderneming en die enkele tientallen koffie-ondernemingen den strijd om het bestaan niet kunnen volhouden in dezen moeilijken tijd.

Daartegenover staat nu de zich steeds verder ontwikkelende kleinlandbouw als een hoopvol verschiet voor de toekomst.

Regelmatig en zonder schokken is die ontwikkeling niet geweest. Ook daarbij zijn ernstige tegenslagen ondervonden. Ik denk aan de aanvankelijke mislukking der Creolenkolonisatie bij Lelydorp aan de spoorlijn, waar de gronden niet vruchtbaar genoeg bleken voor deze kolonisten en eerst later in handen van Javanen een geslaagden vorm van kleinlandbouw vertoonden. De grootste tegenslag voor de grondjesbewoners was de ondergang van de cacaocultuur, die voor velen, vooral in het Saramaccadistrict, hoofdbron van hun bestaan was. Als gevolg daarvan trokken velen ontmoedigd naar de stad.

Ondanks deze tegenslagen vertoont de kleinlandbouw, vooral in de laatste 20 jaren een gestadigen groei. Enkele voorbeelden mogen dit verduidelijken. 
De vroeger onbeteekenende rijstproductie nam aanvankelijk langzaam toe: in 1900 bedroeg de productie 285 ton padi, in 1912 nog slechts 2500 ton, in 1932 was deze echter gestegen tot 25000 ton, dus het tienvoudige van de productie in 1912. De invoer van 60.000 balen rijst in de topjaren was vervangen door een uitvoer van bijna 30.000 balen in 1932 .

In dezelfde richting wijzen de cijfers, welke het koloniaal verslag over 1932 geeft betreffende de opbrengsten van den grooten en den kleinen landbouw. Voor den grooten landbouw worden deze gesteld op $f$ 2.086.000.-, terwijl de cijfers voor den kleinen landbouw een totaal aanwijzen van $f$ 1.771.000.- zonder de opbrengsten van vee en pluimvee. Daar in 1932 rond 300.000 K.G. rundvleesch van inheemsch vee en rond 80.000 K.G. varkensvleesch van inheemsche varkens in het abattoir te Paramaribo verwerkt werden, waarbij dan nog komen de opbrengsten van melk, kippen en eieren, kan veilig gezegd worden, dat in 1932 de opbrengst van den kleinlandbouw die van den grootlandbouw heeft overtroffen.

De toename van de landelijke bevolking, welke aan deze productie ten grondslag ligt, blijkt ook uit de bevolkingscijfers. Nog altijd doet een bijna onbewoond en weinig productief land als Suriname met een stad als Paramaribo als centrum denken aan een kind met een waterhoofd, maar gelukkig is er een zichtbare verbetering in de verhoudingen.

In 1900 bedroeg de stadsbevolking van Paramaribo 32.000 zielen, terwijl de landelijke bevolking 37.000 zielen telde. In 1932 was de eerste gestegen tot 49.000 zielen, terwijl de landelijke bevolking - ondanks den achteruitgang der plantages tot 88.000 was toegenomen. Tegenover een toename van de stadsbevolking met rond $50 \%$, staat dus een toename der districtsbevolking met bijna $150 \%$.

Zooals boven reeds werd opgemerkt, heeft het Bestuur doelbewust de kolonisatie ter hand genomen, omdat het ontbreken van een gevestigde landbouwende bevolking en de veel te geringe bevolkingsdichtheid als de grootste hinderpalen voor de ontwikkeling van Suriname erkend werden. Vooral de Gouvernementsvestigingsplaatsen - groote, door het Bestuur ingerichte polders met huurperceelen van \pm 2 H.A. - hebben hier baanbrekend gewerkt. Na een periode van proefnemingen en gedeeltelijke mislukkingen zijn deze uiteindelijk een succes geworden en is bij de opgezetenen op tal van plaatsen een langzaam toenemende welvaart te constateeren, welke zich uit in het bezit 
van betere woningen, meer vee, enz., en, naar den voor hen geldenden maatstaf, betrekkelijke welvaart.

Enkele cijfers mogen weer den groei doen uitkomen.

In 1900 waren er 997 perceelen op Gouvernementsvestigingsplaatsen uitgegeven, in 1932 was dit getal tot 8432 gestegen.

Buiten de vestigingsplaatsen waren in 1900 uitgegeven, meest aan Creolen, 1899 perceelen, welk getal in 1932, inzonderheid door vestiging van Britsch-Indiërs en Javanen, tot 7627 was toegenomen.

Vooral de wat afzetgebied betreft gunstig gelegen vestigingsplaatsen dicht bij Paramaribo toonen, hoeveel hier reeds bereikt is. De vestigingsplaats Meerzorg bijv. tegenover Paramaribo op den rechter Suriname-oever, waar ongeveer 1200 H.A. geheel in cultuur zijn, maakt door de flinke houten huizen met zinken daken der oudere kolonisten en door een veebezit van \pm 800 koeien, een gunstigen indruk.

Dat men hier op den goeden weg is, blijkt ook uit het volgende.

De Gouvernementsvestigingsplaatsen hebben navolging gevonden bij particuliere plantagebezitters, waarvan er verschillende hun terreinen verkavelden en aan Britsch-Indiërs en Javanen verhuurden. Daarnaast gingen Javanen zelf spontaan tot het vormen van een belangrijke nederzetting over, welke zich met geringe bestuurshulp snel uitbreidde.

De klacht, welke periodiek van planterszijde gehoord wordt, dat de vestigingsplaatsen weinig vrije arbeiders leveren, wijst er op, dat de kleinlandbouwers in het algemeen van de opbrengst van hun grond leven kunnen. Ik voeg er echter dadelijk bij, dat dit nog niet overal het geval is, met name niet op jonge of ongunstig gelegen nederzettingen.

Ter typeering van de sociaal-economische omzetting, welke met dezen principieelen ombouw van den landbouw gepaard gaat, zij nog op het volgende gewezen. Bij de behandeling van het Regeeringsreglement van Suriname in de Tweede Kamer in 1854 werd de vrees uitgesproken, dat de Koloniale Staten, waarin immers de planters de meerderheid zouden vormen, te weinig oog zouden hebben voor de belangen van de voormalige slaven. Thans is de toestand zoo, dat in deze Staten niet één planter meer zitting heeft, maar juist de belangen van den kleinen man met bijzondere zorg door dit college behartigd worden.

Tenslotte stellen wij ons de vraag, wat verder noodig is om den kleinlandbouw tot ontwikkeling te doen komen en tot een gezonde basis voor den opbouw van Suriname te maken. 
Ter voorkoming van misverstand zij vooraf opgemerkt, dat mijnerzijds de beteekenis van den grootlandbouw allerminst wordt onderschat. Ook deze moet, indien eenigszins mogelijk in stand gehouden worden. Voorshands is zij, met name voor den export, van meer beteekenis dan de kleinlandbouw. Maar voor de toekomst geloof ik, dat de laatste grootere mogelijkheden biedt en minder risico.

Op vier dingen wijs ik in dit verband.

In de eerste plaats is hetgeen thans op het gebied van kolonisatie bereikt is, nog slechts een begin. Een bevolking van 160.000 zielen voor een gebied zoo groot als Java is nog zoo ten eenenmale onvoldoende, dat met ernst moet worden voortgegaan op den weg van bevolkingsvermeerdering. Een driemaal grootere bevolking zou b.v. praktisch geen verhooging van kosten voor bestuur, rechtspraak, enz. veroorzaken.

In de tweede plaats lijdt de kleinlandbouw evenzeer als de grootlandbouw door het gemis van een voldoend aantal uitvoerproducten. Het is, nu de binnenlandsche markt in allerlei opzichten overvoerd raakt, een levenskwestie, loonende uitvoerproducten te vinden, daar ook de kleinlandbouwer, die van eigen producten leeft, daarnaast een bescheiden geldinkomen niet missen kan. Rijst kan op den duur een loonend uitvoerproduct zijn met onbegrensde mogelijkheden, wanneer het gelukt de kwaliteit te verbeteren. De voorloopige resultaten met tabak (productie in 1932 reeds 3400 K.G.), sinaasappelen en bacoven zijn hoopgevend. Hier ligt nog een dankbare taak voor het proefstation, al zullen tegenvallers ook daarbij niet uitblijven.

Een derde behoefte van den kleinlandbouw is een goed wegennet, niet slechts voor het vervoer der producten, maar vooral ook voor het bewoonbaar maken der districten. De rivieren mogen goede afvoerwegen zijn voor massaproducten, voor kleinvervoer hebben zij, vooral door de sterke getijbeweging, zeer groote bezwaren. Maar vooral voor het opheffen van het isolement der districtsbewoners zijn wegen noodig. Dit behoeft gelukkig geen nader betoog meer, daar deze behoefte thans algemeen erkend wordt. Sedert Gouverneur Staal in 1918 zijn wegenplan opstelde, is in deze richting, vooral in de laatste jaren, reeds veel bereikt, maar meer blijft er nog te doen overig. Daarbij hoede men zich voor de fout van het perfectionisme, die ons Hollanders, ook op koloniaal gebied, altijd bedreigt. Het thans noodige voor Suriname zijn niet autosnelwegen, zooals Nederland die op het oogenblik bouwt, maar wegen, die minder intensief bereden 
worden dan de tertiaire wegen in Nederland en waaraan geen hoogere eischen gesteld mogen worden, dan dat zij het geheele jaar door de communicatie mogelijk maken. Gaat men verder en stelt men hoogere eischen, dan laat zich met zekerheid voorspellen, dat het voor Suriname noodige wegenplan niet binnen afzienbaren tijd kan worden afgewerkt. Gelukkig heeft de Directeur van Openbare Werken en Verkeer in Suriname ten deze een juisten kijk op de verhoudingen en weet hij met de inheemsche materialen voor $f$ 10.000.- per K.M. (inclusief kunstwerken) de wegen aan te leggen, die Suriname op dit oogenblik noodig heeft.

Het vierde punt, ten aanzien waarvan nog vele moeilijkheden overwonnen moeten worden, betreft de assimilatie van de Aziatische kleinlandbouwers in de Surinaamsche gemeenschap. Van dit veelzijdige vraagstuk stip ik slechts enkele onderdeelen aan.

De Aziatische kleinlandbouwers, zonen van analphabeten, moeten opgenomen worden in de Nederlandsch-Creoolsche cultuurgemeenschap, welke gegroeid is uit een oorspronkelijke kolonistengemeenschap. Het uitgangspunt was een op Europeanen ingestelde samenleving en nog tot in de tweede helft der 19e eeuw bleven bestuur, rechtspraak en onderwijs in hoofdzaak daarop ingesteld. Daarin zijn de Creolen, mede dank zij Zending en Missie, opgenomen. Sedert 1876 bestaat de leerplicht op de Hollandsche lagere school voor alle bevolkingsgroepen. Hoe moet nu de inpassing van Britsch-Indiërs en Javanen in dat geheel zijn? Ook zij zullen de Nederlandsche taal moeten overnemen, omdat de groepen te klein zijn om hun eigen taal te kunnen handhaven. Hoe moeten verschillende instellingen gebracht worden op een peil, dat overeenstemt met de economische mogelijkheden van deze bevolkingsgroepen, die nu reeds $50 \%$, straks misschien $75 \%$ of meer der bevolking uitmaken? Hoe moet uit deze onsamenhangende massa eenlingen zonder historischen achtergrond een organische samenleving met dorpen of waterschappen gevormd worden?

Zietdaar eenige der moeilijke vragen, welke bij den verderen uitbouw van den kleinen landbouw om oplossing vragen.

Ook die oplossing zal zonder twijfel gevonden worden, zij het niet op korten termijn en zonder vallen en opstaan.

Bedriegen de voorteekenen niet, dan is het tot dusver verkregen resultaat met de vestiging van kleinlandbouwers in Suriname - en ik reken daartoe ook de nog altijd in de districten landbouwende Creolen, met name in Coronie - een der weinige 
geslaagde experimenten in dit zwaar beproefde gebiedsdeel, waardoor hoopgevende perspectieven geopend worden voor den verderen ombouw van Suriname van plantagekolonie tot een normale samenleving met een stevig agrarisch fundament van kleinlandbouwers. 